\title{
Improved current transport properties of post annealed Y1Ba2Cu307-x thin films using Ag doping
}

Clausen, Thomas; Skov, Johannes; Jacobsen, Claus Schelde; Bukh, K R; Bollinger, Mikkel; Tobiasen, B. P.; Sager, M. P.; Chorkendorff, Ib; Larsen, J

Published in:

Journal of Applied Physics

Link to article, DOI:

10.1063/1.361473

Publication date:

1996

Document Version

Publisher's PDF, also known as Version of record

Link back to DTU Orbit

Citation (APA):

Clausen, T., Skov, J., Jacobsen, C. S., Bukh, K. R., Bollinger, M., Tobiasen, B. P., Sager, M. P., Chorkendorff, I., \& Larsen, J. (1996). Improved current transport properties of post annealed Y1Ba2Cu3O7-x thin films using Ag doping. Journal of Applied Physics, 79(9), 7062-7068. https://doi.org/10.1063/1.361473

\section{General rights}

Copyright and moral rights for the publications made accessible in the public portal are retained by the authors and/or other copyright owners and it is a condition of accessing publications that users recognise and abide by the legal requirements associated with these rights.

- Users may download and print one copy of any publication from the public portal for the purpose of private study or research.

- You may not further distribute the material or use it for any profit-making activity or commercial gain

- You may freely distribute the URL identifying the publication in the public portal 


\title{
Improved current transport properties of post annealed $\mathrm{Y}_{1} \mathrm{Ba}_{2} \mathrm{Cu}_{3} \mathrm{O}_{7-x}$ thin films using Ag doping
}

\author{
T. Clausen, J. L. Skov, C. S. Jacobsen, K. R. Bukh, M. V. Bollinger, B. P. Tobiasen, \\ and M. P. Sager \\ Physics Department, Technical University of Denmark, Bldg. 309, DK-2800 Lyngby, Denmark \\ I. Chorkendorff and J. Larsen \\ Physics Department, Technical University of Denmark, Bldg. 307, DK-2800 Lyngby, Denmark
}

(Received 31 July 1995; accepted for publication 2 January 1996)

\begin{abstract}
The influence of Ag doping on the transport properties of $\mathrm{Y}_{1} \mathrm{Ba}_{2} \mathrm{Cu}_{3} \mathrm{O}_{7-x}$ thin films prepared by $\mathrm{Y}$, $\mathrm{BaF}_{2}$, and $\mathrm{Cu}$ co-evaporation and optimized ex situ post annealing has been investigated. Both undoped and Ag doped films have values of $T_{c}$ above $90 \mathrm{~K}$, but $J_{c}(77 \mathrm{~K})$ is highly dependent on the nominal thickness $\left(t_{\text {nom }}\right)$ of the as-deposited film. For undoped films with $t_{\text {nom }} \leqslant 300 \mathrm{~nm} J_{c}$ (77 K) $\left(\gg 10^{6} \mathrm{~A} / \mathrm{cm}^{2}\right)$ decreases monotonically with increasing film thickness. Above $300 \mathrm{~nm} J_{c}(77 \mathrm{~K})$ decreases rapidly to values below $5 \times 10^{5} \mathrm{~A} / \mathrm{cm}^{2}$. Ag doped films with $t_{\text {nom }} \geqslant 200 \mathrm{~nm}$ have higher $J_{c}$ $(77 \mathrm{~K})$ values than those of undoped films. Ag doped films have a maximum in $J_{c}(77 \mathrm{~K})$ around $250 \mathrm{~nm}$. As for the undoped films, there is a large decrease in $J_{c}(77 \mathrm{~K})$ for Ag doped films with $t_{\text {nom }} \geqslant 300 \mathrm{~nm}$. It was found that the higher values of $J_{c}(77 \mathrm{~K})$ for the Ag doped films were due to a better epitaxial growth of the YBCO compound. The low values of $J_{c}(77 \mathrm{~K})$ for both undoped and Ag doped single layer films with $t_{\text {nom }} \geqslant 300 \mathrm{~nm}$ were found to be due to the absence of 1-2-4 inclusions in these films. Based on these findings high $J_{c}(77 \mathrm{~K})$ films with $t_{\text {nom }}>300 \mathrm{~nm}$ were grown by successive deposition and annealing of films with $t_{\text {nom }}<300 \mathrm{~nm}$ on top of each other. A $2 \times 150 \mathrm{~nm}$ undoped film was found to have a $J_{c}(77 \mathrm{~K})$ value of $4,1 \times 10^{6} \mathrm{~A} / \mathrm{cm}^{2}$. This is almost a doubling of the $J_{c}(77 \mathrm{~K}$ ) value as compared to the value for the $300 \mathrm{~nm}$ single layer undoped film $\left(2,2 \times 10^{6} \mathrm{~A} / \mathrm{cm}^{2}\right)$. Ag doped double layer films of $2 \times 150 \mathrm{~nm}$ and $2 \times 215 \mathrm{~nm}$ had comparable $J_{c}(77$ $\mathrm{K})$ values $\left(5,8 \times 10^{6}\right.$ and $5,6 \times 10^{6} \mathrm{~A} / \mathrm{cm}^{2}$, respectively). In comparison with the undoped $2 \times 150 \mathrm{~nm}$ film $J_{c}(77 \mathrm{~K})$ is thus further increased (by about 50\%) when doping with Ag. (C) 1996 American Institute of Physics. [S0021-8979(96)03208-2]
\end{abstract}

\section{INTRODUCTION}

High- $T_{c}$ superconducting $\mathrm{Y}_{1} \mathrm{Ba}_{2} \mathrm{Cu}_{3} \mathrm{O}_{7-x}(\mathrm{YBCO})$ thin films can be grown by several techniques. The $\mathrm{BaF}_{2}$ coevaporation technique has proven superior in combination with optimized ex situ post annealing at low oxygen partial pressures. ${ }^{1-7}$ In general, films processed under these conditions have a good surface morphology with no large surface outgrowths, high transition temperatures $\left(T_{c}\right)$, high values of the critical current density $\left(J_{c}\right)$ and good microwave properties. ${ }^{3-7}$ These good properties can be obtained only if the YBCO thin films are grown on special substrates. Good lattice matching in the $a-b$ plane is necessary to reduce film strain and encourage 1-2-3 YBCO $c$-axis growth. Furthermore, it is important for the substrate to be able to withstand the high processing temperatures $\left(750-900{ }^{\circ} \mathrm{C}\right)$ and the annealing environment in order to reduce interdiffusion between the YBCO and the substrate elements. It has been shown that $\mathrm{LaAlO}_{3}$ satisfies these requirements for the $\mathrm{BaF}_{2}$ co-evaporation process, with ex situ post annealing incorporating a wet oxidation step. ${ }^{5,8}$ On the other hand, we have found that $\mathrm{MgO}$ substrates degrade in the wet environment leading to $\mathrm{Mg}$ diffusion into the growing $\mathrm{YBCO}$ film, and as a result of that the superconducting properties degrade $\left(T_{c} \approx 82-84 \mathrm{~K}\right){ }^{9}$

Doping of YBCO have been studied intensively ever since the discovery of the high $T_{c}$ 1-2-3 YBCO compound. ${ }^{10-25}$ For instance, by doping YBCO with Ag or
Au both $T_{c}$ and $J_{c}$ can be enhanced depending on the growth parameters. The incorporation of $\mathrm{Ag}$ into $\mathrm{YBCO}$ has been postulated to give several effects; (i) improved values of $J_{c}$ due to intergranular diffusion of $\mathrm{Ag}$ resulting in reduced contact resistance between the superconducting grains, ${ }^{11,15,17,19}$ (ii) a larger amount of the YBCO film is $c$-axis oriented ${ }^{13,21}$ also resulting in improved values of $J_{c}$ and (iii) if the annealing temperature exceeds the melting point of the $\mathrm{Ag} / \mathrm{YBCO}$ phase, the Ag atoms can diffuse into the YBCO lattice and substitute $\mathrm{Cu}$ atoms at the $\mathrm{Cu}(1)$ sites. The $\mathrm{Ag}$ atom thereby bonds to an additional electron, thus increasing the hole concentration resulting in an increased $T_{c} \cdot{ }^{22}$

Recently Pinto et al. ${ }^{13}$ have demonstrated improved microwave performance of $\mathrm{Ag}$ doped pulsed laser deposition (PLD) YBCO thin film (thickness; $200 \mathrm{~nm}$ ) microbridge resonators. They found that grain boundary weak links in undoped YBCO films are the main reason for large values of the surface resistance $\left(R_{s}\right)$ and its dependence on the microwave input power levels. ${ }^{13}$ They ascribed the better microwave performance of the $\mathrm{Ag}$ doped films to a better epitaxy of the films in accordance with other reports on the subject. ${ }^{13,19-21}$ In this paper, we study the effect of Ag doping of YBCO thin films grown using the $\mathrm{BaF}_{2}$ coevaporation process and ex situ post annealing.

It is a general observation that $J_{c}$ decreases somewhat with increasing film thickness for ex situ post annealed YBCO films. ${ }^{6,7,23,26}$ This behavior has been explained by a 
TABLE I. Results on stoichiometric check on $500 \mathrm{~nm}$ thick Ag doped YBCO film with ICP and EDAX.

\begin{tabular}{ccccc}
\hline \hline Element & $\begin{array}{c}\text { Stoichiometric } \\
\text { compound } \\
\text { (at. \%) }\end{array}$ & $\begin{array}{c}\text { ICP } \\
\text { Ag-YBCO } \\
\text { (at. \%) }\end{array}$ & $\begin{array}{c}\text { ICP } \\
\text { bulk-YBCO } \\
\text { (at. \%) }\end{array}$ & $\begin{array}{c}\text { EDAX } \\
\text { Ag-YBCO } \\
\text { (at. \%) }\end{array}$ \\
\hline $\mathrm{Y}$ & 7.69 & 7.31 & 7.84 & 7.49 \\
$\mathrm{Ba}$ & 15.38 & 15.53 & 15.07 & 15.41 \\
$\mathrm{Cu}$ & 23.08 & 23.31 & 23.23 & 23.24 \\
$\mathrm{O}$ & 53.85 & $\mathrm{NA}^{\mathrm{a}}$ & $\mathrm{NA}^{\mathrm{a}}$ & NA $^{\mathrm{a}}$ \\
\hline \hline
\end{tabular}

${ }^{a}$ NA means that the information is not available from the technique used. For the calculation we have assumed that the oxygen content $x$ is close to 7 .

decreasing density of $1-2-4$ stacking faults with increasing film thickness assuming that the stacking faults act as core type flux pinning centers. ${ }^{26}$ In this paper, we show that the 1-2-4 phases more likely make an additional contribution to $J_{c}$ below $80 \mathrm{~K}$ and we report on a novel technique that circumvents the problem on decreasing $J_{c}$ with increasing film thickness. The novel technique employs a fabrication of YBCO films in sequential steps, i.e., make multiple film deposition and annealing steps.

\section{EXPERIMENT}

The thin films $\left[150 \mathrm{~nm} \leqslant t_{\text {nom }}\right.$ (nominal film thickness) $\leqslant 500 \mathrm{~nm}$ ] were deposited by co-evaporation of $\mathrm{Y}$ $(99,9 \%)$ and $\mathrm{Cu}(99,999 \%)$ from electron guns and $\mathrm{BaF}_{2}$ $(99,9 \%)$ from an effusion cell onto polished $8 \times 8 \mathrm{~mm}^{2}$ and $10 \times 10 \mathrm{~mm}^{2}(100) \mathrm{LaAlO}_{3}$ substrates in a Vacuum Generators UHV chamber with a base pressure of less than $10^{-9}$ Torr. During deposition the chamber pressure increased to about $5 \times 10^{-7}$ Torr. The substrates were rotated at $10 \mathrm{rpm}$ and were held close to room temperature $\left(27^{\circ} \mathrm{C}\right)$ during deposition. The stoichiometry of the as-deposited films were controlled by monitoring the evaporation rates and checked for each deposition using the inductive coupled plasma (ICP) technique and energy dispersive $\mathrm{x}$-ray analysis (EDAX). In Table I are shown a typical result of a stoichiometric check with ICP and EDAX for a bulk YBCO piece compared with a $500 \mathrm{~nm} \mathrm{Y}-\mathrm{BaF}_{2}-\mathrm{Cu}$ thin film coated with $\mathrm{Ag}$. Within a few percent, the film has the right stoichiometric ratio (Table I).

Ex situ post annealing was performed in a quartz tube furnace (with quartz getters) using a two-step annealing technique consisting of a high temperature step followed by a lower temperature step. The first step was a one hour annealing at a temperature of $800{ }^{\circ} \mathrm{C}$ in a $\mathrm{Ar}-\mathrm{O}_{2}$ mixture flow of $1000 \mathrm{sccm}$. The oxygen partial pressure, $p\left(\mathrm{O}_{2}\right)$, was $100 \mathrm{~Pa}$ and the gas was bubbled through deionized $\mathrm{H}_{2} \mathrm{O}$ starting at $775^{\circ} \mathrm{C}$ during ramp up $\left(20^{\circ} \mathrm{C} / \mathrm{min}\right)$ and ending also at $775^{\circ} \mathrm{C}$ during ramp down $\left(5^{\circ} \mathrm{C}\right.$ min $)$. The second step was a one hour annealing at $525^{\circ} \mathrm{C}$ in 1 atm dry oxygen with a flow rate of $200 \mathrm{sccm}$. Switching from the low- $p\left(\mathrm{O}_{2}\right)$ to the high $p\left(\mathrm{O}_{2}\right)$ regime was done at $550{ }^{\circ} \mathrm{C}$ during ramp down. The Ag doping (5 wt \%) was achieved by coating the amorphous $\mathrm{Y}_{1}\left(\mathrm{BaF}_{2}\right)_{2} \mathrm{Cu}_{3}$ film with $\mathrm{Ag}(99,999 \%)$ overlayers prior to the ex situ post annealing.
The superconducting properties of the annealed films were evaluated by measuring the zero resistance transition temperature $\left(T_{c}\right)$ and the critical current density $\left(J_{c}\right)$ for temperatures ranging from $50 \mathrm{~K}$ to $88 \mathrm{~K}$. The surface morphology was examined by scanning electron microscopy (SEM) and atomic force microscopy (AFM). The degree of the intergranular diffusion of $\mathrm{Ag}$ into the $\mathrm{YBCO}$ lattice and the crystalline quality of the YBCO film were studied with Auger electron spectroscopy (AES) and X-ray diffraction (XRD), respectively.

The measurement of $T_{c}$ was done by measuring the dependence of film resistivity on temperature $(77-300 \mathrm{~K})$ by a standard four-point probe technique using a lock-in-amplifier (PAR Model 186 SYNCHRO-HET). Indium bits were pressed in contact with the film in order to minimize the contact resistance between the probes and the superconductor. Typical current levels were around $10 \mu \mathrm{A}$. The $a-b$ plane $J_{c}(T)$ was determined from ac-magnetization experiments. The sample was mounted close to one of two balanced pick-up coils (diameter $5 \mathrm{~mm}$ ) which were suspended in a $6 \mathrm{~Hz}$ ac magnetic field. The signal $S(t)$ from the pick-up coils was recorded, time integrated and plotted against the excitation signal $A(t)$, thereby obtaining magnetization hysteresis loops. $J_{c}$ was evaluated from the height of the magnetization loops (self-field conditions). In general, this gives a value of $J_{c}$ which is somewhat lower than what is measured using a current-voltage $(I-V)$ characterization method, because no voltage criterion is set in the magnetization experiments.

Scanning electron microscopy for near-surface imaging of the YBCO films was performed using a $30 \mathrm{keV}$ primary electron beam from a Phillips XL20 instrument equipped with an energy dispersive x-ray analysis facility. Atomic force microscopy was performed using a constant force method on an AFM Rasterscope ${ }^{\mathrm{TM}} 4000$ DME instrument.

Phase identification was done with $\mathrm{x}$-ray diffraction using a Phillips PW 1710 O-2Ө diffractometer with diverging slits. The sample holder for the x-ray diffractometer was made from polystyrene with a recess for placing the samples. The samples were mounted with wax and aligned with respect to the $\mathrm{CuK}_{\alpha}$ beam by pressing the samples gently in place with another polystyrene plate face to face with the sample holder. $2 \Theta$ was scanned from $10^{\circ}$ to $90^{\circ}$ with a scan rate of $0.6 \% \mathrm{~min}$. A PHI 590 A scanning Auger microprobe (SAM) with a base pressure of less than $2 \times 10^{-10}$ Torr, combined with in situ argon ion milling, was used to study the compositional properties of the YBCO/Ag films. The Auger spectra were obtained with a $10 \mathrm{keV}$ primary beam corresponding to a beam spotsize of a few microns. The $\mathrm{Ar}^{+}$ sputtering ion energy was $2 \mathrm{keV}$ and the fluency was 25 $\mathrm{mA} \mathrm{cm}{ }^{-2}$. During the various sputtering cycles the operating pressure was increased from about $2 \times 10^{-10}$ to $2 \times 10^{-7}$ Torr by leaking argon gas into the working chamber. Atomic concentration profiles were obtained from the Auger spectra by using standard table sensitivity factors for all the involved atomic elements at the chosen energy of the primary beam. 


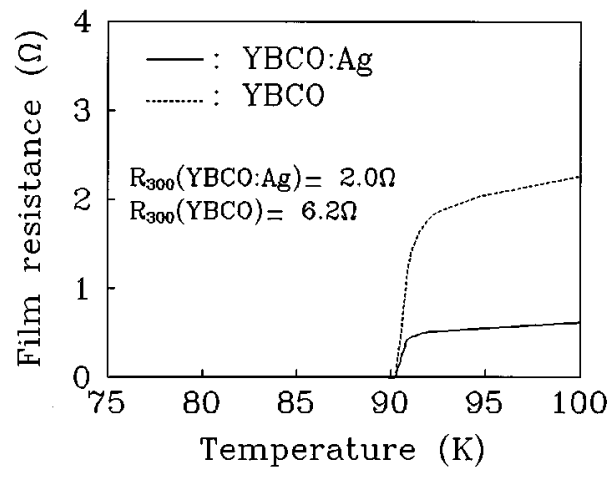

FIG. 1. Film resistance vs temperature for undoped $300 \mathrm{~nm}$ film (dashed line) and Ag doped $300 \mathrm{~nm}$ film (solid line).

\section{RESULTS}

For the undoped films we found that $T_{c}>90 \mathrm{~K}$ with a transition width $\Delta T_{c}<1 \mathrm{~K}$ (Fig. 1). The best films had $T_{c}$ 's just below $92 \mathrm{~K}\left(t_{\text {nom }}>300 \mathrm{~nm}\right)$. The ratio between the film resistance at $300 \mathrm{~K}$ and the film resistance at $100 \mathrm{~K}$ was below $3(2.7-2.9)$ for the undoped films. $J_{c}(77 \mathrm{~K})$ was found to decrease with increasing nominal film thickness with $J_{c}(77 \mathrm{~K})$ values ranging from $2.0 \times 10^{5} \mathrm{~A} / \mathrm{cm}^{2}$ to $4.5 \times 10^{6} \mathrm{~A} / \mathrm{cm}^{2}$ (Fig. 2). As can be seen from Fig. 2, there is a large decrease in $J_{c}(77 \mathrm{~K})$ for films with $t_{\text {nom }}>300 \mathrm{~nm}$. For a $1 \mu \mathrm{m}$ wide microbridge this means that the maximum critical current is about $7 \mathrm{~mA}(77 \mathrm{~K})$ for films with $t_{\text {nom }} \leqslant 300$ $\mathrm{nm}$, while for films with $t_{\mathrm{nom}}>300 \mathrm{~nm}$, the maximum critical current that can be carried is only about $1 \mathrm{~mA}(77 \mathrm{~K})$. McIntyre et $a l .{ }^{26}$ have found, for ex situ post annealed chemically derived films, that a maximum critical current of about $5 \mathrm{~mA}$ can be applied to a microbridge of $1 \mu \mathrm{m}$ width irrespective of the film thickness $(<500 \mathrm{~nm})$. Thus, the growth mode for our films seems to change when the film thickness exceeds $300 \mathrm{~nm}$. This change in growth mode can probably be shifted to a larger thickness if the annealing conditions are further optimized as it has been reported by Hou et al. ${ }^{7}$ However, high values of $J_{c}(77 \mathrm{~K})\left(\gg 10^{6} \mathrm{~A} / \mathrm{cm}^{2}\right)$ are not expected for undoped films with $t_{\text {nom }} \geqslant 400 \mathrm{~nm}$ even when the annealing conditions are further optimized. ${ }^{7}$

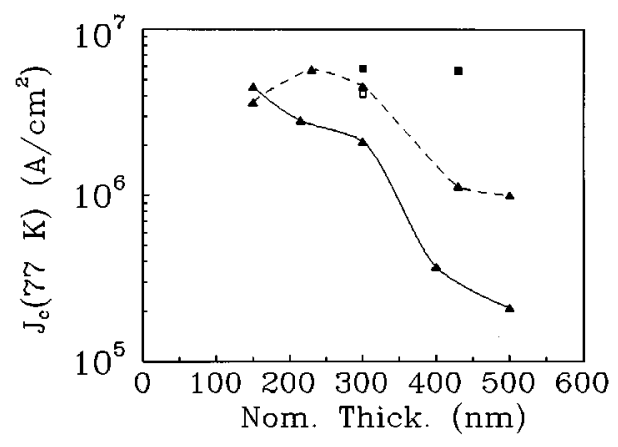

FIG. 2. Critical current density measured at $77 \mathrm{~K}, J_{c}$ (77 K), vs the nominal film thickness for undoped films (solid line), Ag doped films (dashed line), undoped double layer film (open square), and Ag doped double layer films (filled squares). Lines are guides for the eye.

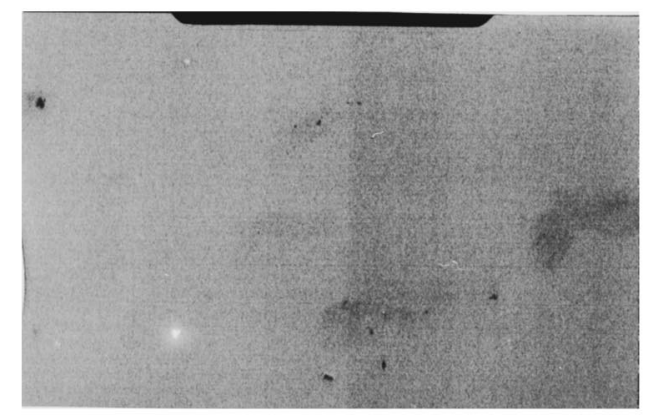

a) $\longmapsto 5 \mu \mathrm{m}$

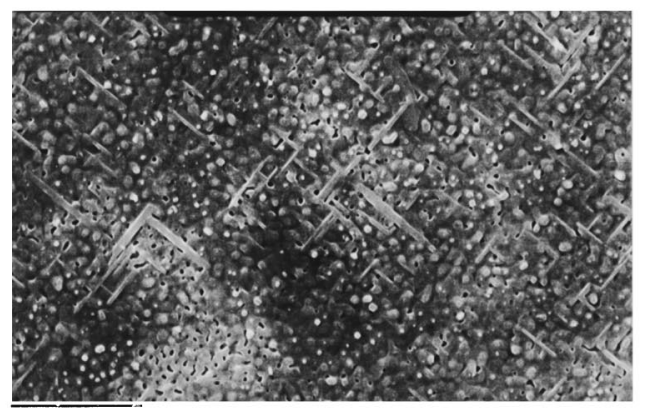

b) $\longmapsto 5 \mu \mathrm{m}$

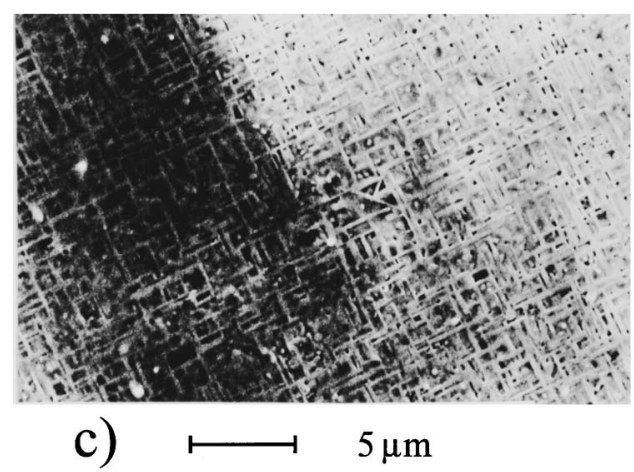

FIG. 3. SEM pictures of surface morphology of undoped films with different film thicknesses, (a) $150 \mathrm{~nm}$, (b) $300 \mathrm{~nm}$, and (c) $500 \mathrm{~nm}$.

SEM pictures of the surface morphology of the undoped films are shown in Fig. 3. $150 \mathrm{~nm}$ films are smooth with no visible surface structures [Fig. 3(a)] When the film thickness is increased $a-b$ axis surface structures become visible [Fig. 3(b)] and for films with $t_{\text {nom }}>300 \mathrm{~nm}$ the $a-b$ surface structures cover all of the surface [Fig. 3(c)] Hou et al. ${ }^{7}$ have found a similar surface morphology behavior when comparing ex situ post annealed films of different thicknesses. They also found that $J_{c}$ decreases with increasing film thickness. ${ }^{7}$

For the Ag doped films, we also found that $T_{c}>90 \mathrm{~K}$ with $\Delta T_{c}<1 \mathrm{~K}$ (Fig. 1). These films showed good metallicity with a ratio between the film resistance at $300 \mathrm{~K}$ and the film resistance at $100 \mathrm{~K}$ being close to 3. Again, the best films had $T_{c}$ 's just below $92 \mathrm{~K}\left(t_{\text {nom }}>300 \mathrm{~nm}\right)$. For $\mathrm{Ag}$ doped 
films with $t_{\text {nom }}>150 \mathrm{~nm} J_{c}(77 \mathrm{~K})$ was significantly improved in comparison with undoped single layer films, but for the $150 \mathrm{~nm} \mathrm{Ag}$ doped film $J_{c}(77 \mathrm{~K})$ was lower than what could be obtained for an undoped film (Fig. 2). As can be seen from Fig. 2, $J_{c}(77 \mathrm{~K})$ has a maximum around a $250 \mathrm{~nm}$ Ag doped film $\left(5.7 \times 10^{6} \mathrm{~A} / \mathrm{cm}^{2}\right)$. For the microbridge device described previously this means that a maximum critical current of $14 \mathrm{~mA}(77 \mathrm{~K})$ can be carried for $\mathrm{Ag}$ doped films with thicknesses between $250-300 \mathrm{~nm}$. This is a doubling of the current carrying capacities in comparison with the capacities for undoped films. As was the case for the undoped films, the growth mode also seems to change with increasing thickness for the Ag doped films as seen by the low values of $J_{c}(77 \mathrm{~K})$ for Ag doped films with $t_{\text {nom }}>300 \mathrm{~nm}$ (Fig. 2). If optimized with respect to the annealing conditions, we believe that values of $J_{c}(77 \mathrm{~K})$ well above $10^{6} \mathrm{~A} / \mathrm{cm}^{2}$ can be achieved for 400-500 $\mathrm{nm} \mathrm{Ag} \mathrm{doped} \mathrm{films,} \mathrm{but} \mathrm{the} \mathrm{current} \mathrm{carrying} \mathrm{ca-}$ pacities for a device will probably remain close to that of the 200-300 nm Ag doped films.

SEM and AFM pictures of the surface morphology of the Ag doped films are shown in Fig. 4 and Fig. 5, respectively. As can be seen, droplets have nucleated on the surface of an otherwise hard and smooth film. From EDAX measurements, it was found that the droplets consisted mostly of $\mathrm{Ag}$ with less than 1 at $\% \mathrm{Ag}$ in the underlying YBCO matrix. From AFM (Fig. 5), it was found that the height of a large number of the droplets exceeded the nominal YBCO film thickness. The droplets were only loosely bound to the YBCO film and were easily removed with for instance a pair of tweezers or a light rinse/etch [Fig. 4(c)]. From AES experiments (Fig. 6), it was found that the Ag droplets extend into the YBCO film [Fig. 6(a)], while outside the droplet region the film was quite homogeneous with little $\mathrm{Ag}$ in the YBCO matrix [Fig. 6(b)]. Note that the right stoichiometric ratio between $\mathrm{Y}, \mathrm{Ba}$, and $\mathrm{Cu}(1: 2: 3)$ can not be obtained from Fig. 6(b). This is in contrast to the findings in Table I, where we find the right stoichiometric ratio using ICP and EDAX. The discrepancy is due to the sensitivity factors used for the calculation of the atomic concentrations in the AES plots (Fig. 6), and has recently been corrected by Selvam. ${ }^{26}$

XRD experiments on undoped and $\mathrm{Ag}$ doped $500 \mathrm{~nm}$ films (Fig. 7) showed that both were preferentially $c$-axis oriented with a somewhat higher yield (30\%) from the $(00 l)$ planes for the Ag doped film. When calculating the $c$-axis length on the basis of the position of the $(00 l)$ reflections, it was found that $c_{\text {undoped }}=11.70 \AA$ and $c_{\text {Ag-doped }}=11.68 \AA$. The expanded $c$-axis length for the undoped $500 \mathrm{~nm}$ film indicates that the epitaxy is better (larger grain size/smaller grain boundary angle/stress relaxation) for the $\mathrm{Ag}$ doped $500 \mathrm{~nm}$ film. Alternatively, the difference in the $c$-axis length for the two films can be explained by a different oxygen content in the YBCO phase. In any case, they can both explain the difference in $J_{c}(77 \mathrm{~K})$ between the undoped and $\mathrm{Ag}$ doped films. We will return to this point in the next section where we discuss the results in more detail.

In addition to the YBCO $(00 l)$ diffraction peaks several impurity peaks were found (Fig. 7). The main impurity peaks were identified as $1-2-4(h 00)$ and $(h h 0)$ diffraction peaks, but also small amounts of 2-1-1 phases were detected from
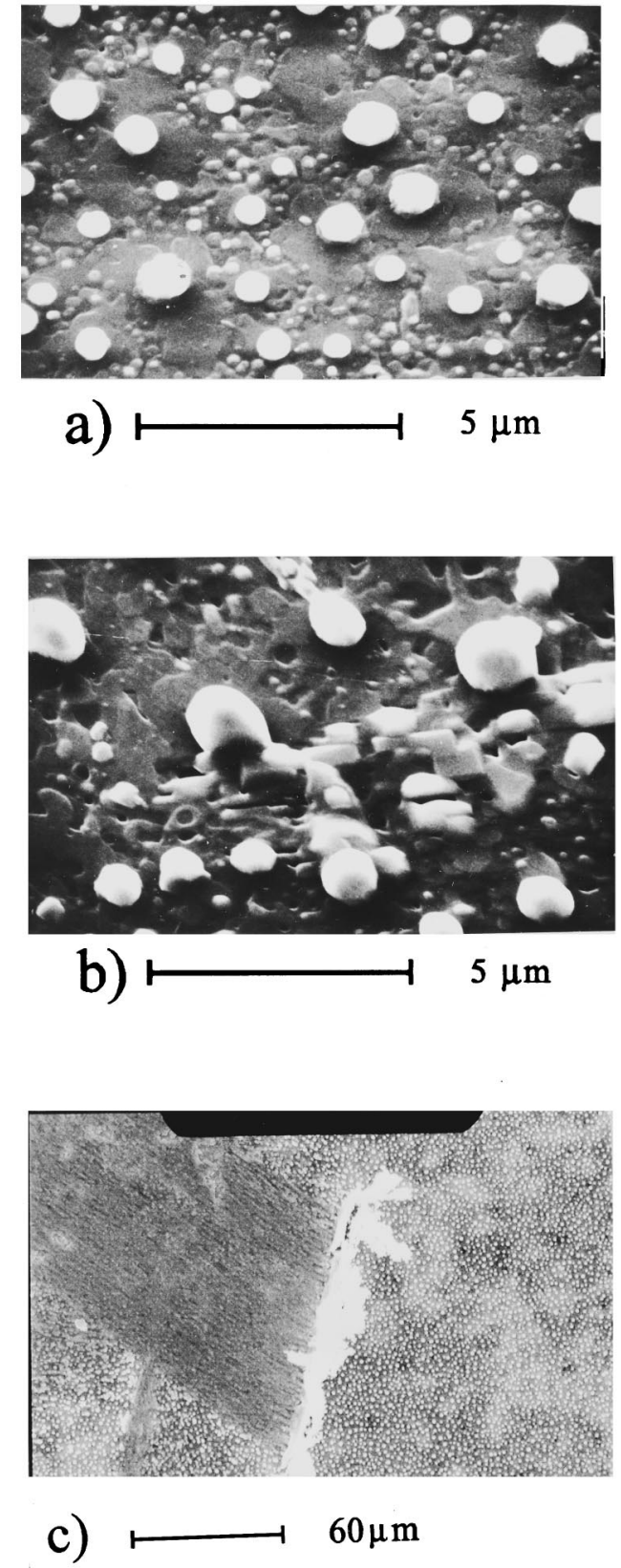

FIG. 4. SEM pictures of surface morphology of Ag doped films, (a) $250 \mathrm{~nm}$, (b) $430 \mathrm{~nm}$, and (c) Ag droplets have been removed with a pair of tweezers. Note the different length scales.

XRD (Fig. 7). These impurity phases with their corresponding orientational behavior have been observed by other authors studying post annealed YBCO films. ${ }^{27-29}$ The influence of these impurity phases on the current transport properties will also be discussed in more detail in the next section.

\section{DISCUSSION}

Transport properties of post annealed YBCO thin films are sensitive to the thickness of the as-deposited films and the annealing parameters. This is clear from our results presented above and the results of several other groups. ${ }^{1-7,27-29}$ McIntyre et al. have reported on the $J_{c}$ dependence of film thickness for similar post annealed films. ${ }^{27}$ They showed that there is a correlation between the density of 1-2-4 stacking 


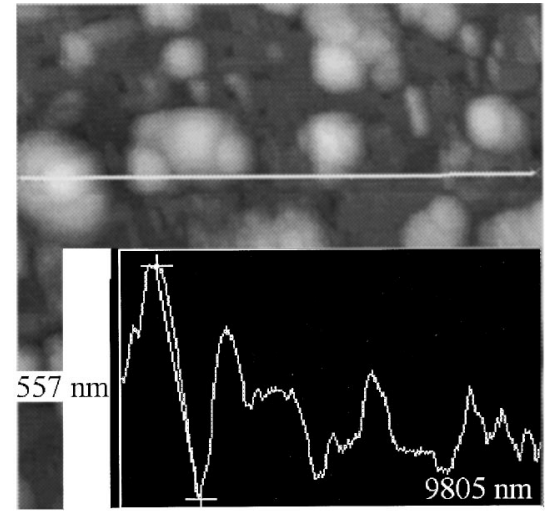

FIG. 5. AFM picture of surface morphology of Ag doped film. The inset shows a line surface roughness scan across the surface (white line on the AFM picture).

faults and $J_{c}$ in that the 1-2-4 stacking faults act as planar core type flux pinning centers thereby increasing $J_{c}$. They also found that the density of stacking faults decreases with increasing film thickness for post annealed films because of a change in the growth mode. ${ }^{27}$ This is in accordance with Clemens et al. who have found that the 1-2-4 preferentially nucleates at the substrate/film interface. ${ }^{29}$ Thus, $J_{c}$ is expectedly higher for thinner post annealed films. We have studied the dependence of $J_{c}$ in the temperature range from $50-88 \mathrm{~K}$ for different samples (Fig. 8). The samples represent two types of growth; namely (i) a film with a thickness below $300 \mathrm{~nm}$ (this film is expected to have a large number of 1-2-4 inclusions) and (ii) a film with a thickness above 300
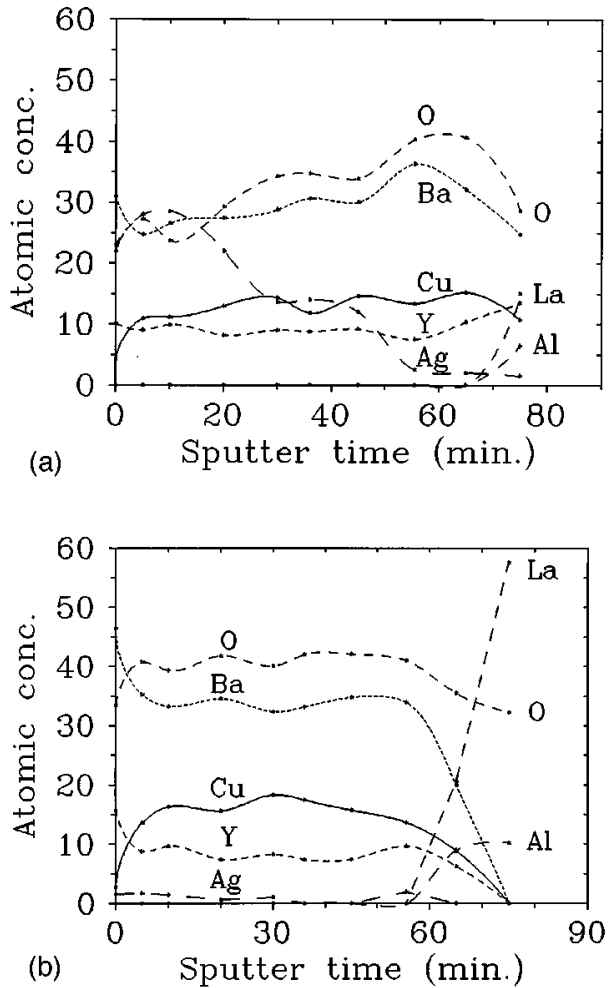

FIG. 6. AES sputter depth profiles of an Ag doped film (a) on a droplet and (b) between the droplets. Standard sensitivity factors were used to calculate the atomic concentrations.

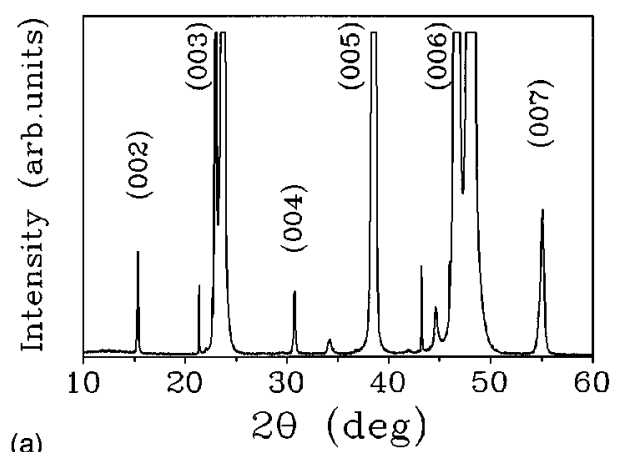

(a)

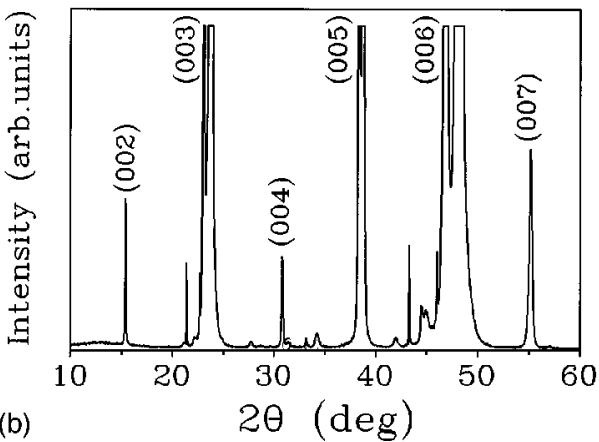

FIG. 7. XRD $\theta-2 \theta$ scans of YBCO films, (a) undoped $500 \mathrm{~nm}$ film and (b) Ag doped $500 \mathrm{~nm}$ film.

$\mathrm{nm}$ (this film is expected to consist primarily of the 1-2-3 phase with only a small density of $1-2-4$ inclusions). From Fig. 8, it is seen that there is a kink in the curve at $T \approx 79 \mathrm{~K}$ for the two films that are expected to contain a large density of 1-2-4 inclusions. This indeed indicates the presence of 1-2-4 phases in these films since this phase becomes superconducting around $80 \mathrm{~K}$. The $J_{c}-T$ curve for the single layer $430 \mathrm{~nm}$ film is smooth and that film is therefore believed to have only a small density of 1-2-4 inclusions that can contribute to the total value of $J_{c}$. The results presented in Fig. 8 thus explains the low values of $J_{c}$ for films with a thickness above $300 \mathrm{~nm}$ for Ag doped and undoped films (Fig. 2). For films with a thickness below $300 \mathrm{~nm}, J_{c}$ has contributions both from the $1-2-3$ phase $\left(<T_{\mathrm{c}}\right)$ and the $1-2-4$ phase $(<80 \mathrm{~K})$.

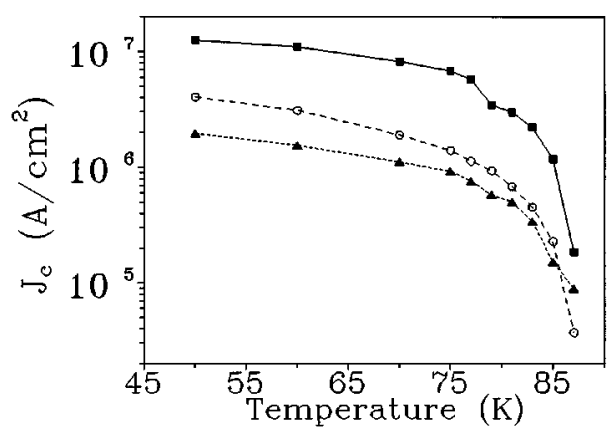

FIG. 8. Critical current density, $J_{c}$ vs temperature for Ag doped films; solid line: $250 \mathrm{~nm}$ film, long dashed line: $430 \mathrm{~nm}$ film and short dashed line: 300 $\mathrm{nm}+430 \mathrm{~nm}$ double layer film. 
Optimum annealing conditions for post annealed YBCO thin films have been reported by Siegal et al. ${ }^{5}$ and Hou et $a .^{7}$ They find that there are two optimum lines in the $p\left(\mathrm{O}_{2}\right)-T$ diagram depending on the desired property of the YBCO thin film. If a good crystalline film is wanted in preference to a film with a high value of $J_{c}$, a higher annealing temperature is required for a given oxygen partial pressure. ${ }^{5,7}$ As described in the experimental section, our films are annealed in an oxygen partial pressure of $100 \mathrm{~Pa}$ at $800^{\circ} \mathrm{C}$. This means, in terms of the results of Siegal et al..$^{5}$ and Hou et al., ${ }^{7}$ that we are $25^{\circ} \mathrm{C}$ below the optimum temperature for good crystalline films, but $50{ }^{\circ} \mathrm{C}$ above the optimum temperature for high $J_{c}$ films. However, we are annealing in the optimum processing window for $\mathrm{BaF}_{2}$ post annealed films as defined by Hou et al. ${ }^{7}$ Moreover, we are annealing for one hour while both Siegal et al. ${ }^{5}$ and Hou et al. ${ }^{7}$ annealed their films for only $30 \mathrm{~min}$. The difference in annealing time may change the position of the two optimum lines since the annealing time is a very important parameter in obtaining good quality films.

The 1-2-4 phase can be stabilized by the use of lower temperatures for a given oxygen partial pressure, ${ }^{30}$ but for the temperature and the oxygen partial pressure that we use the $1-2-3$ phase is the only stable phase. ${ }^{30}$ Still, $1-2-4$ inclusions are found that have distinct normalsuperconducting properties (Figs. 2, 7, and 8). The optimum line for high values of $J_{c}$ is shifted towards lower temperatures for a given oxygen partial pressure at the cost of a deteriorated crystal quality. ${ }^{5,7}$ We believe that this optimum is governed by the creation of 1-2-4 inclusions in the 1-2-3 crystal. Beyond the optimum line for high values of $J_{c}$ (i.e., lower temperatures) more 1-2-4 inclusions form that significantly reduces both $T_{c}$ and $J_{c}, T_{c}$ decreases to a lower value in the presence of 1-2-4 inclusions. $T_{c}$ changes from just over $90 \mathrm{~K}$ for $150-300 \mathrm{~nm}$ films (with 1-2-4 inclusions) to values well above $91 \mathrm{~K}$ for films with a thickness above $400 \mathrm{~nm}$ (with little or no 1-2-4 inclusions).

Ag doped films in general show a significant improvement in $J_{c}(77 \mathrm{~K})$ in comparison with undoped films. Above a thickness of $250 \mathrm{~nm}$ the $\mathrm{Ag}$ doped and undoped films have a similar dependence on the thickness of the as-deposited film. From SEM, AFM, and AES analyses it was shown that Ag nucleates in droplets which are dispersed across the film. The droplets extend into the YBCO film and the total thickness of the droplets exceeds that of the YBCO film. The droplets can thus be thought as effective vertical pinning centers that pin flux vortices along their length when a current is passed through the film. XRD showed that the epitaxy of the YBCO film did benefit from Ag doping. This suggests that the improved transport properties for Ag doped films with a thickness above $200 \mathrm{~nm}$ is not entirely due to pinning effects but also due to an improved growth of YBCO. Although it is difficult to conclude from our experiments which mechanism is most responsible for the improved behavior, the formation of smaller-angle junctions, larger grain sizes, and relaxation of residual stresses in the YBCO film caused by $\mathrm{Ag}$ are the most probable mechanisms. The $150 \mathrm{~nm}$ film did not benefit from Ag doping. On the contrary the $\mathrm{Ag}$ doped $150 \mathrm{~nm}$ film had worse transport properties than did

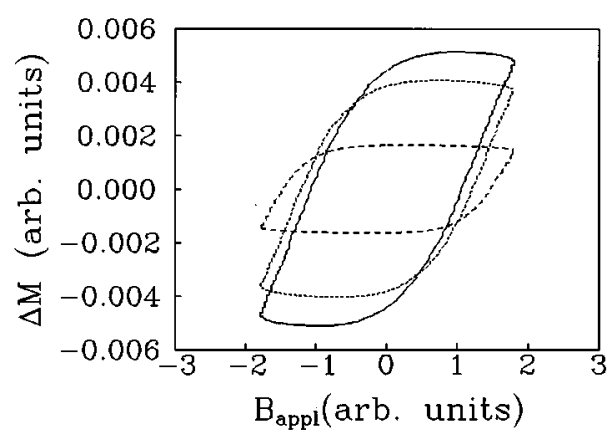

FIG. 9. Magnetization curves for $150 \mathrm{~nm}$ undoped films with different annealing parameters; solid line: $800^{\circ} \mathrm{C} / 60 \mathrm{~min}+525^{\circ} \mathrm{C} / 60 \mathrm{~min}$, short dashed line: $800{ }^{\circ} \mathrm{C} / 15 \mathrm{~min}+525^{\circ} \mathrm{C} / 60 \mathrm{~min}$, long dashed line: $800{ }^{\circ} \mathrm{C} / 15 \mathrm{~min}$ $+525^{\circ} \mathrm{C} / 15 \mathrm{~min}$.

the undoped $150 \mathrm{~nm}$. This could be due to thickness variations in the as-deposited very thin $\mathrm{Ag}$ layer for the $150 \mathrm{~nm}$ films or the very thin Ag layer may not have been continuous.

Based on the results from the single layer films (Figs. $1-8)$, there is a possibility that $J_{c}$ can be further increased for films with $t_{\text {nom }}>300 \mathrm{~nm}$ by growing a YBCO multilayer film. The multilayer film should thus consist of several layers with a thickness ranging from 150 to $300 \mathrm{~nm}$ and after each deposition the film should be annealed. The previously used annealing profile can not be used directly because of the total thermal budget. We have studied the effects on $J_{c}(77 \mathrm{~K})$ by changing the time at the two annealing steps on undoped single layer films with a thickness of $150 \mathrm{~nm}$. The results (Fig. 9 and Table II) show that a decrease in time of the high annealing step at $800^{\circ} \mathrm{C}$ does not seriously affect the value of $J_{c}(77 \mathrm{~K})$. However, if the time at the low annealing step at $525^{\circ} \mathrm{C}$ is decreased the value of $J_{c}(77 \mathrm{~K})$ is significantly reduced (Fig. 9 and Table II). Therefore, an annealing profile with $15 \mathrm{~min}$ at $800{ }^{\circ} \mathrm{C}$ and $60 \mathrm{~min}$ at $525^{\circ} \mathrm{C}$ was chosen in order to reduce the total thermal budget for the multilayer film.

A double layer film $\left(t_{\text {nom }}=2 \times 150 \mathrm{~nm}\right)$ was grown with the deposition/annealing technique discussed above. The film was found to have a value of $J_{c}(77 \mathrm{~K})$ of $4.1 \times 10^{6} \mathrm{~A} / \mathrm{cm}^{2}$ (Fig. 2). This value is almost twice the value of $J_{c}(77 \mathrm{~K})$ for a $300 \mathrm{~nm}$ single layer film $\left[J_{c}(77 \mathrm{~K})=2.2 \times 10^{6} \mathrm{~A} / \mathrm{cm}^{2}\right.$ (Fig. 2)]. Compared to a $\mathrm{Ag}$ doped single layer film with a thickness of $300 \mathrm{~nm}\left[J_{c}(77 \mathrm{~K})=4.5 \times 10^{6} \mathrm{~A} / \mathrm{cm}^{2}\right.$ (Fig. 2)], we find that the $J_{c}$ values are almost the same. This implies that a further enhancement of $J_{c}$ can be achieved by doping the multilayer film with Ag. The SEM and AFM pictures (Figs.

TABLE II. Effect on $J_{c}(77 \mathrm{~K})$ by changing the annealing time at both the annealing step $\left(800^{\circ} \mathrm{C}\right)$ and the oxygenation step $\left(525^{\circ} \mathrm{C}\right)$.

\begin{tabular}{cccc}
\hline \hline $\begin{array}{c}\text { Annealing parameters } \\
\left({ }^{\circ} \mathrm{C}\right) /(\min )\end{array}$ & $\begin{array}{c}\text { Film thickness } \\
(\mathrm{nm})\end{array}$ & $\begin{array}{c}T_{c} \\
(\mathrm{~K})\end{array}$ & $\begin{array}{c}J_{c}(77 \mathrm{~K}) \\
\mathrm{A} / \mathrm{cm}^{2}\end{array}$ \\
\hline $800 / 60+525 / 60$ & 150 & 89.6 & $4.5 \times 10^{6}$ \\
$800 / 15+525 / 60$ & 150 & 89.9 & $3.5 \times 10^{6}$ \\
$800 / 15+525 / 15$ & 150 & 89.1 & $1.4 \times 10^{6}$ \\
\hline \hline
\end{tabular}




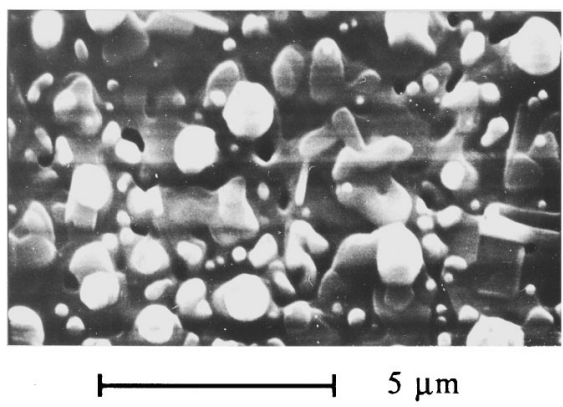

FIG. 10. SEM pictures of surface morphology of Ag doped $300 \mathrm{~nm}+430$ $\mathrm{nm}$ double layer film.

4 and 5) of the annealed Ag doped single layer films showed that the Ag nucleates in droplets on the surface of the YBCO. The Ag doped double layer film can thus be grown by (i) depositing a $\mathrm{Y}_{1}\left(\mathrm{BaF}_{2}\right)_{2} \mathrm{Cu}_{3}$ film on the $\mathrm{LaAlO}_{3}$ substrate; (ii) covering the film with $\mathrm{Ag}$ (iii) annealing using the double layer annealing procedure; (iv) depositing a new $\mathrm{Y}_{1}\left(\mathrm{BaF}_{2}\right)_{2} \mathrm{Cu}_{3}$ film; and (v) annealing using the double layer annealing procedure. The $\mathrm{Ag}$ droplets on top of the first YBCO layer are used as dopant material in the second YBCO layer matrix. With $t_{\text {nom }}=2 \times 150 \mathrm{~nm} \mathrm{YBCO} \mathrm{and} \mathrm{Ag}$ deposited between the layers, a $J_{c}(77 \mathrm{~K})$ value of $5.8 \times 10^{5}$ $\mathrm{A} / \mathrm{cm}^{2}$ was achieved (Fig. 2). $J_{c}$ is thus improved by $50 \%$ compared with the undoped double layer film (Fig. 2). With $t_{\text {nom }}=2 \times 215 \mathrm{~nm}$ YBCO and Ag deposited between the layers, a $J_{c}\left(77 \mathrm{~K}\right.$ ) value of $5.6 \times 10^{6} \mathrm{~A} / \mathrm{cm}^{2}$ was achieved (Fig. 2 ). This value is five times the value for the Ag doped single layer $430 \mathrm{~nm}$ film, and is an order magnitude larger than the value for the undoped single layer $400 \mathrm{~nm}$ film (Fig. 2). In terms of the microbridge device introduced above this means that a maximum current of almost $25 \mathrm{~mA}$ can be applied without affecting the superconductivity of the device. We have thus compensated for the large decrease in $J_{c}(77 \mathrm{~K})$ for films with $t_{\text {nom }}>300 \mathrm{~nm}$.

In a similar experiment, an $\mathrm{Ag}$ doped double layer 730 $\mathrm{nm}$ film was grown consisting of a first layer of $300 \mathrm{~nm} \mathrm{Ag}$ doped film and a second layer of $430 \mathrm{~nm}$ film. The annealing was done using the prescriptions outlined above. The film was hard but had extended surface structures (Fig. 10). However, $J_{c}(77 \mathrm{~K})$ was quite low with a value of $7.6 \times 10^{5} \mathrm{~A} / \mathrm{cm}^{2}$ (Fig. 8). From Fig. 8 it seems there is a small kink in the $J_{c}-T$ curve at $79 \mathrm{~K}$ indicating the presence of $1-2-4$ inclusions. These inclusions are probably present only in the first $300 \mathrm{~nm}$ layer. This experiment thus shows that the multilayer films should indeed be fabricated from films with $t_{\text {nom }}<300$ nm.

\section{CONCLUSIONS}

In summary, we have shown that the current carrying capacities of post annealed YBCO thin films can be improved by doping with $\mathrm{Ag}$ prior to the annealing. This improvement is primarily due to a better epitaxial structure of the YBCO film in the presence of Ag during growth. Also, we have shown that the value of $J_{c}(77 \mathrm{~K})$ is critically dependent on the presence of a large number of 1-2-4 inclusions in the 1-2-3 matrix irrespective of the doping characteristics (undoped/Ag doped) and the growth method (single layer/ multilayer). The 1-2-4 inclusions become superconducting around $80 \mathrm{~K}$ and make a significant contribution to the total supercurrent below that temperature. The formation of 1-2-4 inclusions during the annealing sequence is intimately linked to the annealing temperature $\left(T_{\text {ann }}\right)$, gas pressure $\left(p\left(\mathrm{O}_{2}\right)\right)$ and time $\left(t_{\mathrm{ann}}\right)$.

${ }^{1}$ S.-W. Chan, B. G. Bagley, L. H. Greene, M. Giroud, W. L. Feldmann, K. R. Jenkin, and B. J. Wilkins, Appl. Phys. Lett. 53, 1443 (1988).

${ }^{2}$ X. K. Wang, K. C. Sheng, S. J. Lee, Y. H. Shen, S. N. Song, D. X. Li, R. P. H. Chang, and J. B. Ketterson, Appl. Phys. Lett. 54, 1573 (1989).

${ }^{3}$ M. P. Siegal, J. M. Phillips, R. B. van Dover, T. H. Tiefel, and J. H. Marshall, J. Appl. Phys. 68, 6353 (1990).

${ }^{4}$ A. Mogro-Campero, L. G. Turner, A. M. Kadin, and D. S. Mallory, Appl. Phys. Lett. 60, 3310 (1992).

${ }^{5}$ M. P. Siegal, S. Y. Hou, J. M. Phillips, T. H. Tiefel, and J. H. Marshall, J. Mater. Res. 7, 2658 (1992).

${ }^{6}$ A. Mogro-Campero, L. G. Turner, A. M. Kadin, and D. S. Mallory, J. Appl. Phys. 73, 5295 (1993).

${ }^{7}$ S. Y. Hou, J. M. Phillips, D. J. Werder, T. H. Tiefel, J. H. Marshall, and M. P. Siegal, J. Mater. Res. 9, 1936 (1994).

${ }^{8}$ R. W. Simon, C. E. Platt, A. E. Lee, G. S. Lee, K. P. Daly, M. S. Wire, J. A. Luine, and M. Urbanik, Appl. Phys. Lett. 53, 2677 (1988).

${ }^{9}$ Unpublished results.

${ }^{10}$ M. Z. Cieplak, G. Xiao, C. L. Chien, J. K. Stalick, and J. J. Rhyne, Appl. Phys. Lett. 57, 934 (1990).

${ }^{11}$ R. K. Singh, D. Bhattacharya, P. Tiwari, J. Narayan, and C. B. Lee, Appl. Phys. Lett. 60, 255 (1992).

${ }^{12}$ T. Kumagai, T. Manabe, W. Kondo, S. Mizuta, and K. Arai, Appl. Phys. Lett. 61, 988 (1992).

${ }^{13}$ R. Pinto, N. Goyal, S. P. Pai, P. R. Apte, L. C. Gupta, and R. Vijayaraghavan, J. Appl. Phys. 73, 5105 (1993).

${ }^{14}$ S. S. Ata-Allah, Y. Xu, and C. Heiden, Physica C 221, 39 (1993).

${ }^{15}$ A. K. Pradhan, B. K. Roul, V. V. Rao, and V. R. Kalvey, Cryogenics 33, 910 (1993).

${ }^{16}$ C. N. van Huong, M. Nicolas, A. Dubon, and C. Hinnen, J. Mater. Sci. 28, 6418 (1993).

${ }^{17}$ M. J. Day, S. D. Sutton, F. Wellhofer, and J. S. Abell, Supercond. Sci. Technol. 6, 96 (1993).

${ }^{18}$ D. Veretnik and S. Reich, Physica C 223, 227 (1994).

${ }^{19}$ D. Kumar, M. Sharon, P. R. Apte, R. Pinto, S. P. Pai, S. C. Purandare, C. P. D'Souza, L. C. Gupta, and R. Vijayaraghavan, J. Appl. Phys. 76, 1349 (1994).

${ }^{20}$ P. R. Apte, R. Pinto, A. G. Chourey, and S. P. Pai, J. Appl. Phys. 75, 4258 (1994)

${ }^{21}$ R. Pinto, P. R. Apte, M. S. Hedge, and D. Kumar, J. Appl. Phys. 77, 4116 (1995).

${ }^{22}$ A. Sen and H. S. Maiti, Physica C 229, 188 (1994).

${ }^{23}$ T. Clausen, M. Ejrnaes, M. Olesen, K. Hilger, J. L. Skov, P. Bodin, A. Kühle, and I. Chorkendorff, Appl. Phys. Lett. 65, 2350 (1994).

${ }^{24}$ E. Yanmaz, I. H. Mutlu, T. Kucukomeroglu, and M. Altunbas, Supercond. Sci. Technol. 7, 903 (1994).

${ }^{25}$ A. Lanckbeen, P. H. Duvigneaud, P. Diko, M. Mehbod, G. Naessen, and R. Deltour, J. Mater. Sci. 29, 5441 (1994).

${ }^{26}$ P. Selvam, Appl. Phys. Lett. 67, 3650 (1995).

${ }^{27}$ P. C. McIntyre and M. J. Cima, J. Mater. Res. 9, 2778 (1994).

${ }^{28}$ A. F. Marshall, K. Char, R. W. Barton, A. Kapitulnik, and S. S. Laderman, J. Mater. Res. 5, 2049 (1990).

${ }^{29}$ B. M. Clemens, C. W. Nieh, J. A. Kittl, W. L. Johnson, J. Y. Josefowicz, and A. T. Hunter, Appl. Phys. Lett. 53, 1871 (1988).

${ }^{30}$ G. F. Voronin and S. A. Degterov, Physica C 176, 387 (1991). 